4

(C) 2011

\title{
Professor Yun Sik Kwak
}

Dr. Yun Sik Kwak, age 73, Professor of Medical Informatics at Samsung Medical Center, died of a sudden heart attack in his office on November 23, 2010.

He was born on August 21, 1937, in the city of Daegu, Korea. He graduated with an MD from the Kyungpook National University School of Medicine in Daegu, Korea in 1961 and earned a $\mathrm{PhD}$ in Molecular Biology and Pathology from Albany Medical College, Albany, NY, USA. From 1969 through 1995, he served on the faculties of Albany Medical College; the Case Western Reserve University School of Medicine, Cleveland, $\mathrm{OH}$; and the Wright State University School of Medicine, Dayton, OH. He returned to Korea, his homeland, in 1994 to head the Clinical Pathology Department at the Ajou University School of Medicine in Suwon until 1999. Then, he created the Medical Informatics Department at the Ajou University School of Medicine, and served as its head until 1999. He also created the Medical Informatics Department at the Kyungpook National University School of Medicine, where he worked as an invited professor until 2010. Prior to his death, he joined Samsung Medical Center as a Professor and Senior Advisor of Medical Informatics and helped set up the Biomedical Informatics program within the Department of Health Sciences and Technology at Sungkyunkwan University.

Dr. Kwak was one of the most prominent figures within the international healthcare information technology standards communities. From 2003 to 2009, he was the Chair of the ISO technical committee ISO/TC 215, Health Informatics, and devoted himself to promoting the development of health informatics in Asia, and in the world. Dr. Kwak was instrumental in founding JIC, which is a collaborations of health informatics SDOs - including ISO, CEN, and HL7, now expanded with CDISC, IEEE - to work together to harmonize their efforts. He also chaired HL7 Korea from 2001, and recently organized the HIMSS AsiaPac 2010 held in Daegu, Korea in October 2010. He was passionate about and promoted international standards, including ISO and HL7, throughout many HIT projects including the Center for Interoperable EHR, the Intelligent Health Information Sharing System Development Center, the Biobank of Korea, the IHE Korea Connectathon, and the health information exchange (HIE) in general.

Dr. Kwak served the Korean Society of Medical Informatics (KOSMI) for many years in different positions. He was a vice president of the KOSMI from 1998-2001, president-elect from 20022003, president in 2004, and then director of the Research Institute of Medical Informatics affiliated with the KOSMI.

As a respected professor of laboratory medicine, he held chairmanships in several university departments. He was an inspector of the CAP (College of American Pathologists) Laboratory Accreditation Program since 1980 and was the Deputy Regional Commissioner for Far Eastern Civilian Laboratories of the program since 2003. His legacy is still felt in the Korean Laboratory Accreditation Program (KLAP) of the Korean Society for Laboratory Medicine (KSLM), which was initiated by Dr. Kwak and a small group of other enthusiastic clinical pathologists.
Dr. Kwak was a brave soldier as well. He served in the ROK Air Force as a flight surgeon, and later in the US Army as a colonel of the US Army Reserve Medical Command.

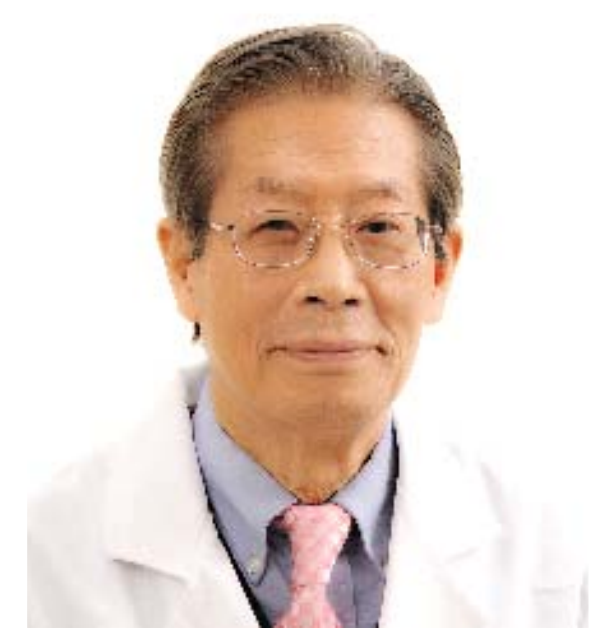

To his family, Dr. Kwak was a loving husband, brother, father, grandfather, uncle, and friend, who gave of himself unselfishly. Dr. Kwak is survived by his loving wife, Pil Nam; his son and his wife Kyung Kyu and Yvette; his daughter and her husband Kyung Yun (Sue) and Jared Northrop; his son Kyung Ho (Kenny); two grandchildren Hong Jae (Alec) and Jae Ik (Colin); two brothers Chun Sik and Jung Sik; and two sisters Eun Ju and Eun Sook.

Funeral services for Dr. Yun Sik Kwak were held at 8:00 a.m., Sunday, November 28, 2010, at the Samsung Medical Center Funeral Home, Irwondong, Seoul, Korea. His body was buried at Jo-Yang Cemetery Park, Chilgok, Korea, the burial site for his family.

Michio Kimura, Hyeoun-Ae Park 